\title{
Publicidade e Consumo Responsável ${ }^{1}$
}

Tarcyanie Cajueiro Santos

Resumo: Da perspectiva sociocultural, a sociedade pautada nos valores do consumo para a conformação das subjetividades se tornou o grande eixo de sentido da vida social. Na publicidade contemporânea, há uma crescente preocupação com o homem e a responsabilização que este passou a ter sobre si próprio e o seu entorno, expressa através de termos como consumo "responsável", ou "sustentável". Ao levar em conta esses dois aspectos, o presente artigo busca refletir sobre as transformações no discurso publicitário e suas relações com o contexto sociocultural. Para tanto, utiliza a metodologia baseada na análise de discurso dos anúncios inspirada em Foucault a partir das noções de biopolítica e de dispositivo desse autor.

Palavras-Chave: consumo responsável; subjetividades; publicidade

Abstract: Advertising and responsible consumption - From the sociocultural point of view, society based on consumer values to conform to subjectivities has become the cornerstone that gives meaning to social life. Contemporary advertising is increasingly concerned with man and his newfound responsibility towards himself and his surroundings, which is expressed through terms such as "responsible" or "sustainable consumption." This article reflects upon the changes in advertising discourse and its relations with the sociocultural context. To this end, we adopt the methodological approach of advertising discourse analysis inspired by Foucault, based on the author's notions of biopolitics and the dispositive.

Keywords: responsible consumption; subjectivities; advertising

\section{A exacerbação das subjetividades nas sociedades de consumo}

As subjetividades passaram a ter grande importância no final do século XX, no qual predominam sociedades estruturadas pela velocidade, caracterizadas pela conectividade das tecnologias informacionais e por um capitalismo globalizado, gerador de uma interdependência crescente. Os discursos que colocam o homem como preocupação primeira abundam em diversas esferas, que vão desde a política, a sociologia até

1 Este artigo é uma versão do trabalho apresentado no DT 2 - Publicidade e Propaganda do XIV Congresso de Ciências da Comunicação na Região Nordeste realizado de 14 a 16 de junho de 2012. 
a economia, cuja "ênfase se desloca da busca da lucratividade máxima para a melhoria da qualidade de vida". Esta podendo ser compreendida como "a possibilidade de se estender à maioria das pessoas o acesso à alimentação, ao trabalho, à saúde, à educação, à cultura, ao lazer e à segurança" (DOWBOR, 2010, p. 104).

Tal pletora do fator humano vem acompanhada da colonização de novas áreas pelo capitalismo, como as da natureza e do inconsciente, que, segundo Jameson, subsistiam invioláveis até os anos 1970. Seguindo as pegadas já balizadas por esse autor, a explosão da esfera cultural perpetrada pela intensificação da "lógica do capitalismo tardio" levou a

uma prodigiosa expansão da cultura por todo o domínio do social, até o ponto em que tudo em nossa vida social - do valor econômico e do poder do Estado às práticas e à própria estrutura da psique - pode ser considerado como cultural, em um sentido original que não foi até agora teorizado (JAMESON, 1996, p.74).

Imbricada com o capitalismo e com o desenvolvimento e extensão das tecnologias de comunicação e informação, a cultura da mídia, em sua complexidade, incide sobre as subjetividades contemporâneas, delegando-as grande importância. Do ponto de vista sociocultural, a sociedade, pautada nos valores do consumo para a conformação das subjetividades, tornou-se o grande eixo de sentido da vida social. A exacerbação das subjetividades, com a sua crescente visibilidade e domínio próprios, tem sido apontada e discutida por diversos pensadores, que as veem numa intensa promiscuidade com o capitalismo, em seu estado atual. Pelbart, ao discorrer sobre a fabricação das subjetividades neste momento da história, aponta para o intenso investimento que o capitalismo vem fazendo sobre ela. O autor chama atenção ao componente sedutor atuante nos fluxos de uma sociedade que consome a si própria numa voracidade ininterrupta. "Não se trata mais de adaptar-se ou obedecer normas, mas de consumir serviços ofertados, que vão desde a dieta até a vida sexual e esportiva. O sujeito não mais se submete a regras, mas ele as investe, como se faz um investimento financeiro: ele quer fazer render (...)" (PELBART, 2000, p. 33).

Diferentemente das sociedades de produção nas quais parecia haver a finalização dos processos, do trabalho e dos projetos, as sociedades de consumo esbarram no prolongamento dos desejos, do trabalho sem fim, da esperança nada secreta de sempre usufruir pílulas de felicidade e afetividade transpostas em bens de consumo e de serviços. E assim, a fabricação de nossas vidas, afetos e formas de sentir pressupõe consumirmos "cada vez mais maneiras de ver e de sentir, de pensar e de perceber, de morar e de vestir, ou seja, formas de vida, e mesmo quando nos referimos aos estratos mais carentes da população, ainda assim essa tendência é crescente" (ibid., p. 34). Nessa relação entre o capitalismo e as novas formas de dominação, os valores afetivos, segundo Pelbart, passam a ocupar um papel central no processo produtivo.

É a partir desse cenário que o presente texto busca refletir sobre as transformações do discurso publicitário e suas relações com o contexto sociocultural. Parte-se do pressuposto 
de que a publicidade é porta-voz de uma irradiação de valores e visões de mundo que integra e perpassa a cultura da mídia, cuja narrativa e imagens veiculadas "fornecem os símbolos, os mitos e os recursos que ajudam a constituir uma cultura comum para a maioria dos indivíduos em muitas regiões do mundo de hoje" (KELLNER, 2001, p. 9). Nesse sentido, enfatiza-se a relação existente entre a preocupação com o homem e a sua responsabilização expressa nos anúncios publicitários, cujos valores se ancoram sob o discurso da sustentabilidade. A responsabilização ocorre pela pletora de participação do consumidor por parte dos anunciantes. Estes, ao mostrarem nos anúncios as suas ações de responsabilidade socioambiental, chamam os consumidores a participarem também, mas, principalmente, por meio do consumo de suas mercadorias.

Este artigo é resultado parcial de uma pesquisa financiada pela Fapesp, na modalidade jovem pesquisador, intitulada "Comunicação, consumo e novas subjetividades: um estudo sobre as práticas mediáticas, culturais e sociais na contemporaneidade". A metodologia utilizada baseou-se na análise de discurso dos anúncios publicados na revista Veja, cuja inspiração vem de Foucault a partir da perspectiva da biopolítica e da noção de dispositivo do autor. Foucault (2008) considera a linguagem central na construção da vida social, sem desconsiderar a importância de uma perspectiva histórica e social sobre as condições de produção dos textos. Por isso, a contextualização histórica e social da emergência da sustentabilidade relaciona-se com o universo discursivo dos anúncios publicitários que focam esse tema. A revista Veja foi escolhida por ser a de maior circulação no país. Os anúncios apresentados fazem parte de uma variedade maior que versam sobre a sustentabilidade, na década de 2000, já analisados, e escolhidos neste artigo como exemplos paradigmáticos que descrevem as manifestações que ilustram tal processo.

\section{O aparecimento da sustentabilidade na publicidade e o consumo responsável}

Seguindo uma tendência internacional, derivada, entre outros fatores, de uma maior competição no mercado, as "grandes marcas" passaram a investir sobremaneira em bens intangíveis. Um exemplo dessa tendência se encontra na mudança do discurso publicitário, que deixou de versar sobre o produto para focar na gestão da comunicação de marcas, tendo como o foco a satisfação dos clientes - o branding, cujo objetivo é "criar valor e fidelidade à marca, fazendo com que ela obtenha e permaneça valorizada no mercado" (IASBECK e PEREIRA, 2011, p.1-2). De tal forma que "saber construir uma marca forte e administrar todos os seus pontos de contato com o cliente, elevando-a a verdadeiros vínculos emocionais é o grande objetivo do gestor de marca" (ibid.).

A ênfase na identidade da marca, que se tornou o principal ativo das empresas, repercute na imagem veiculada pela publicidade e nos valores a ela atrelados. Tais valores captados por meio de planejamento, de pesquisas e pelas agências de publicidade 
são apresentados, desde a década de 1990, conforme Rocha (2005, 2007), sob a forma de responsabilidade social e de qualidade de vida.

Carrilho (2010) também indica o aumento de anúncios que abordam a responsabilidade social e a sustentabilidade nas mensagens publicitárias nos últimos anos, chamando atenção para a influência das mudanças culturais neste processo. Muniz (2004), por sua vez, aponta para a modificação do discurso publicitário, que passa a se apoiar em temáticas sociais. Segundo a autora, a publicidade contemporânea assumiu um papel-chave no capitalismo atual, sendo uma das principais mantenedoras deste sistema.

Os anos 1990, no Brasil, portanto, é o momento em que a publicidade incorpora em sua temática as causas sociais, que vão muito além dos valores da sociedade de consumo por ela tradicionalmente defendidos. Contudo, ao invés de mobilizar uma nova ética, para Muniz, a temática social estaria explicada ao ser associada ao fenômeno-marca, cuja “(...) base impulsionadora da publicidade, absorve todos os valores e experiências sociais, transformando-os em bens de consumo ou mercadorias" (ibid., p. 11).

Isso seria, como defende Rocha (2005), uma resposta do grande capital à opinião pública, que já, a partir dos anos 1980, começou a expressar o seu descontentamento através das suas decisões de compra. A recente importância dada pela publicidade às temáticas sociais atesta o poder que as grandes empresas passaram a ter, com a concomitante desconfiança da opinião pública. Segundo a autora, o "novo consumidor" brasileiro, que emergiu na década de 1980, não se fascinava mais pela industrialização em si, deixando de conceber a esta os créditos pelo avanço da modernização brasileira.

A crise econômica dos anos 1980, nessa perspectiva, teria trazido à baila o fracasso das promessas de modernização construídas ao longo do regime militar, que se expressava, sob o ponto de vista da publicidade, através do apelo ao status e à exaltação a tecnologia. O apelo ao status condizia com uma sociedade regida pela concorrência desenfreada entre os seus pares; a tecnologia, por sua vez, a senha de acesso à tão sonhada modernidade. Juntos, ambos apontavam à "supervalorização dos produtos industrializados", calcados em apelos de "diferenciação" e "hierarquia sociais", que buscavam acelerar o consumo individualizado de mercadorias, constituindo "uma face da redução da modernidade a mero crescimento econômico, porque reduz a promessa de uma modernização mais ampla da sociedade brasileira, cultivada nos anos 1950, em fascínio pela industrialização" (ROCHA, 2005, p. 4). Dito de outra forma, a crise econômica dos anos 1980 colocou em xeque a primazia da ideologia do progresso, manifestada pelo apelo ao status e à tecnologia dos anos 1960 e 1970, abrindo caminho para novos tipos de discursos legitimadores.

Além do esgotamento da ideologia do progresso, Rocha, na esteira de outros autores, também aponta a importância da formação de uma esfera pública brasileira nos idos dos anos 1980, que começou a contestar "o controle exclusivo do Estado pela grande burguesia" (ibid., p. 14), assim como a sua insatisfação com as consequências da política econômica neoliberal, introduzida nos anos 1990. As respostas dadas pelas empresas 
através do discurso publicitário da responsabilidade social, do ponto de vista sociológico, "responde aos custos coletivos da modernização brasileira, em que a industrialização está longe de significar desenvolvimento e bem-estar generalizados" (ROCHA, 2007, p. 17). O conceito de qualidade de vida, por sua vez, "refere-se aos custos pessoais dessa mesma modernização, que produziu novas formas de escassez, como o tempo e as relações puras" (ibid.).

A temática da responsabilidade social é ampliada através da questão ambiental, e a sua preocupação pela preservação da natureza e do próprio homem incorpora valores como os da igualdade, dignidade e felicidade, podendo ser expandida para uma concepção de "cidadania ambiental", que ao "universalizar direitos específicos e especificar direitos universais, sugere uma ampliação radical da noção mais costumeira de cidadania tal como esta tem frequentado discursos e mobilizações sociais" (WALDMAN, 2010, p. 546).

Tal valorização dos ideais modernos se liga com o que muitos autores têm denominado de processo de individualização das sociedades. Se do ponto de vista político-econômico, o avanço do neoliberalismo trouxe uma grande insatisfação em decorrência do déficit de bem-estar social; por outro, sob o ponto de vista subjetivo, levando em conta a perspectiva cultural, sociológica e comunicacional, vivemos "a reintrodução do bem-estar em um estilo de vida em que a tomada de risco, a prioridade da singularidade e o autocontrole definem as normas de conduta de cada um" (EHERENBER, 2010, p.139).

A pergunta que levantamos é: se há uma mudança nos valores expressos nos anúncios publicitários, então, de que forma esses anúncios representam o consumo, já que a responsabilidade socioambiental revestida sob o paradigma da sustentabilidade está supostamente ligada a um tipo de consumo que "atende às necessidades do presente sem comprometer a possibilidade de as futuras gerações atenderem às suas próprias necessidades?" O discurso sustentável em anúncios publicitários "ensina" como devem agir aqueles que desejam ser consumidores responsáveis, mas de que forma isso aparece?

Em relação ao consumo propriamente dito, esse processo inaugura uma fase em que o prestígio, o reconhecimento e o status não mais são a tônica da publicidade. Nesse sentido, ao invés de um consumo regido pela lógica da diferenciação social em que o outro tem importância, teríamos, na perspectiva de autores como Lipovetsky (2007), um consumo hedonista e individualista, no qual prevalecem consumidores "imprevisíveis e voláteis, mais à espera de qualidade de vida, de comunicação e de saúde" (ibid., p. 41), tendo como finalidade a busca da felicidade privada.

Nessa nova lógica, em que as motivações privadas superam as finalidades distintivas, os objetos deixam de ser valorizados como signos tangíveis de sucesso e são percebidos como serviços, cuja finalidade deve ser o consumo para si. Por isso, segundo Lipovetsky (ibid.), a marca se tornou o centro de trabalho de comunicação das empresas. A venda de um estilo de vida associado à marca através do conceito por ela trabalhado é possível devido não apenas ao processo de profissionalização e desenvolvimento do próprio 
setor, como também a perda do valor do status no consumo, pelo menos de como era enfatizado no período anterior. Esse ocaso dos enfrentamentos simbólicos no plano do consumo é partícipe de uma maior soberania individual, que pode ser percebida pela busca de autocontrole e autodomínio por parte dos indivíduos, que se defronta com a gestão ininterrupta de si.

Numa perspectiva muito próxima da nossa, Fontenelle (2010), ao abordar a questão do consumo responsável, chama atenção para a produção de discursos da responsabilização que tem recaído sobre os consumidores ao fazerem suas escolhas; no entanto, "um discurso que remete a uma categoria de consumo moralmente 'sem conflito', limitando a possibilidade de uma discussão sobre as tensões inerentes à questão da escolha a responsabilidade do consumidor'" (FONTENELLE, 2010, p. 216).

Fontenelle, citando Walter Benjamin, defende que esse fenômeno se apresenta como uma "pseudo-redenção" do capitalismo, que estaria ressuscitando socialmente a proibição pessoal e a culpa, enquanto novas mercadorias. A autora aponta para duas possíveis explicações do fenômeno:

(a) da produção social do discurso do 'consumo responsável', tomando-se tal discurso como uma aposta na 'ecologia' enquanto uma nova ideologia, na medida em que se redefinem novos limites externos à possibilidade de acesso igualitário às benesses do progresso capitalista, conforme prometia o projeto de modernidade - e que hoje se esgotou; (b) e do ponto de vista subjetivo, acompanhando-se o debate acerca das perdas de referenciais que ressignificam as subjetividades nos dias que correm (lbid., p. 217).

Esse consumo moralmente "sem conflito", para o qual Fontenelle chama atenção, acontece quando a vida, ela própria, torna-se uma mercadoria. Retomando a abordagem de Tavares e Irving (2009), que se utilizam da noção foucaultiana de biopoder, para o qual o poder produz e reproduz a vida, articulando-se com a sociedade de controle, o consumo responsável apareceria como uma nova "marca" de mercado relacionando-se à ideia de natureza e de sua conservação.

Em seu curso proferido no Collège de France, sobre "o nascimento da biopolítica", Foucault aponta que, desde o final do século XVIII, para a racionalização de problemas específicos da vida e da população, como a saúde, a higiene e a natalidade, decorrentes de uma obsessão pelo liberalismo, seria princípio e método de racionalização de exercício de governo atravessado pelo princípio de "'governar-se sempre demais'" (FOUCAULT, 1997, p. 89). A nova extensão do consumo, por seu lado, que nasce no bojo do capitalismo globalizado e que se amplia sob a forma do mercado verde ou consumo responsável, faz parte de uma "estratégia de regulação social, voltada para a produção de consumo, considerado socioambientalmente correto" (TAVARES e INVRING, 2009, p. 95).

Cabe aqui retomar as análises de Pelbart sobre o assalto do capitalismo às subjetividades, para o qual assistimos a integração da mente na lógica do capital, onde 
são exploradas as dimensões mais imateriais dos homens, especialmente no tocante a essa temática. A natureza sob a ótica da publicidade é transmudada em um capital imaterial, que precisa ser resguardado. Nela, a preocupação com a injustiça social dos padrões de consumo das sociedades ocidentais não transparecem. A natureza aparece nos anúncios como paisagens idílicas, algo que simplesmente precisa ser preservado. Nenhuma menção à problemática ambiental e sua preocupante indissociabilidade com os altos padrões de consumo e estilos de vida de sociedades e classes afluentes, tão propalados na Rio-92, quando os países em desenvolvimento e as ONGs globais advertiram sobre a responsabilidade dos estilos de vida e de uso intensivo de recursos das nações mais ricas do mundo, inaugurando "o segundo deslocamento discursivo que se quer enfatizar nesta análise: dos problemas ambientais causados pela produção para os problemas ambientais causados pelo consumo". (PORTILHO, 2005, p.51).

Tampouco a preocupação enfatizada pela Rio-92 sobre a relação entre o problema mundial da pobreza e a crise ambiental, com a exploração excessiva de recursos naturais, é trabalhada e nem sequer mencionada em vários anúncios. Neles, não há menção alguma à noção de justiça ambiental, enquanto uma prática ética e política, cuja preocupação é "associar o reconhecimento das limitações físicas da terra ao reconhecimento do princípio universal de equidade na distribuição e acesso aos recursos indispensáveis à vida humana, associando a insustentabilidade ambiental aos conflitos distributivos e sociais" (ibid., p. 23). Quando muito, fala-se em reposição ambiental, como veremos logo a seguir no anúncio da Peugeot; em produtos ecológicos, como o banco Real, que anuncia os "talões produzidos de maneira ecologicamente correta" (REVISTA VEJA, 8/2/2006); em ações pontuais, como no anúncio da Gradiente (REVISTA VEJA, 01/01/2000), convocando os consumidores a recolherem suas baterias de celulares em pontos de venda ou nas assistências técnicas, para que sejam recicladas no exterior, através de "projeto de recolhimento de baterias Gradiente"; ou em apoio a projetos como o "Crescer", voltado "para educação de jovens de baixa renda", como em um dos anúncios da Basf (REVISTA VEJA, 28/12/2005), que elucida a junção entre desenvolvimento sustentável e responsabilidade social como um de seus valores. Ou ainda aparecem em algumas campanhas publicitárias atores sociais normalmente excluídos, como é o caso da representação de grupos minoritários, que são retratados nas campanhas publicitárias das marcas Natura (Linha Ekos) e Boticário (Linha Bronze Brasil).

Segundo Lucas e Hoff (2006), apesar da preocupação demonstrada com a sustentabilidade sociocultural, ou seja, com o impacto ambiental e cultural sobre as populações afetadas pelo processo de produção de seus produtos, as campanhas publicitárias dessas empresas

"representam as minorias de modo semelhante. Ambas denunciam a nostalgia de uma 'comunidade imaginada': o discurso econômico presente na publicidade se alimenta de um discurso anterior: o do colonizador, cuja perspectiva é a 'de fora', a 'de quem não conhece'. (LUCAS; HOFF, 2006, p.84)". 
Tavares e Irving (2009), assim como Portilho, apontam para o surgimento do ambientalismo empresarial, a partir dos anos 1990, que no início apenas dá um "banho verde" nos seus produtos já fabricados, depois realmente desenvolvem produtos ditos como ecologicamente sustentáveis além de buscar alternativas para diminuir o impacto sobre o meio ambiente. Esse é o caso do anúncio da Peugeot:

A Peugeot está plantando mais de 10 milhões de árvores no Brasil. A natureza agradece. A Peugeot utilizou toda a sua tecnologia para fazer motores dentro das normas mais rígidas de controle de emissão de poluentes. Mas a preocupação com o meio-ambiente não para por aí. Agora ela está investindo 11 milhões de dólares para plantar mais de 10 milhões de árvores na floresta amazônica. Assim vão ser eliminadas da atmosfera toneladas de gás carbônico, melhorando sensivelmente a qualidade do ar (...). (REVISTA VEJA, 01/03/2000).

O anúncio da Bosch é um bom exemplo da junção entre responsabilidade social e estilo de vida presentes no discurso ambiental dos anúncios. Tal como o anúncio da Peugeot, o da Bosch também enfatiza a tecnologia como uma das principais vias de controle da qualidade ambiental através do conceito de inovação. A qualidade de vida é a palavra-chave para o estilo de vida que deve prevalecer através da preservação do planeta. A finalidade não é mais a tecnologia como provedora do progresso como um fim em si mesmo, mas sim da qualidade de vida, que só poderá ser construída com o auxílio de todos. A gestão responsável, por sua vez, aparece com a preservação do ambiente como "estratégia de negócio". Como cenário, é apresentada uma linda paisagem com árvores e um céu azul, que é vista através das janelas transparentes de uma cozinha, na qual aparece uma geladeira e uma mesa com talheres, pratos, taças e guardanapos. Logo no início da página, com grandes letras, a Bosch chama atenção para os conceitos sobre os quais trabalha: estilo e inovação: "A Bosch inventou eletrodomésticos que unem 'estilo' e 'inovação'. E que ajudam a criar a consciência de um mundo melhor". Abaixo da fotografia, em letras pequenas, a Bosch ainda anuncia que:

O estilo de vida desse século é melhorar a qualidade de vida, preservando o planeta. Assim, a Bosch lançou refrigeradores com porta refrigerada que preserva melhor os alimentos e sua saúde, e produtos que consomem o mínimo de água e de energia. Além disso, a Bosch é o único fabricante no Brasil que possui refrigerador 100\% livre de gazes prejudiciais ao meio ambiente. Isso é inovação com consciência. Isso é tecnologia para a vida www.bosch.com.br. (REVISTA VEJA,7/9/2005).

O Banco Real/ABN AMRO, em anúncio na revista Veja (12/09/2005), menciona que "está sempre reinventando a relação do banco com clientes, fornecedores, sociedade e meio ambiente". Legitima as suas ações ecológicas pela conquista de três das seis categorias do Prêmio Eco, entregue por Al Gore, um dos principais expoentes mundiais da questão 
ambiental. Explica detalhadamente o objetivo e a melhoria que a fusão entre os bancos Sudameris e Real trazem, apontando para a relação entre negócio e sustentabilidade e à importância de sua ação através de prêmios ganhos:

Banco Real ganha três das seis categorias do Prêmio Eco promovido pela Amcham. Tão importante quanto o prêmio é saber que sustentabilidade é uma mensagem que começa a ter eco. A prática da sustentabilidade faz parte da estratégia de negócios do Banco Real. Um reconhecimento disso é a conquista do Prêmio Eco em três das seis categorias existentes para empresas de grande porte. Gestão Empresarial para a Sustentabilidade, Consumidores e Clientes e Meio Ambiente. Os prêmios foram entregues por Al Gore, ex-vice-presidente dos Estados Unidos e uma das maiores autoridades mundiais em meio ambiente. O que nos enche de orgulho e demonstra que somos uma empresa comprometida com princípios e práticas de cidadania empresarial, com desenvolvimento sustentável e com ênfase na satisfação de nossos clientes. (REVISTA VEJA, 12/9/2005).

E ainda na outra página, em caixa alta e centralizada, o banco propõe apresentar o seguinte conceito: "verde é a cor do dinheiro". Logo abaixo, apresenta à esquerda da página uma imagem da natureza, com árvores frondosas e uma cachoeira; e à direita, há um texto que faz questão de enfatizar a relação que o banco tem com o meio ambiente, qual seja a de negócio que vem casada com a tecnologia (inovação). Destrinchando o seu conceito:

Preservar o meio ambiente é nosso objetivo como estratégia de negócio. Porque acreditamos que, quando nossas decisões levam em conta o meio ambiente e a sociedade, os negócios geram resultados sustentáveis. O mercado de capitais tem valorizado esses negócios como tendência global. Temos investido em inovação, para viabilizar produtos, serviços e práticas de gestão, como o uso do papel ecologicamente correto em talões de cheques, a assinatura dos princípios do Equador, linhas de crédito socioambientais, que preservam o meio ambiente e estimulam a reflexão sobre o nosso estilo de vida. Integrar valores humanos e ambientais com valores econômicos, trabalhando junto com nossos clientes e fornecedores, assim temos conseguido boas vitórias que justificam uma breve comemoração no dia de hoje. Breve, porque ainda há muito o que fazer para garantir a sustentabilidade de nossos negócios e estilo de vida hoje e amanhã. Para conhecer e fazer parte de nossa jornada, acesse www.bancoreal.com.br ou uma de nossas empresas (REVISTA VEJA, 12/9/2005).

Por sua vez, o anúncio comemorativo de 30 anos da Fiat no Brasil é feito com crianças, porque o anunciante deseja mostrar sua coerência com um passado de liderança em direção a um futuro sustentável. Nesse sentido, a sua liderança vem de mãos dadas com a sua preocupação com um mundo melhor, apontando para os problemas ambientais que afligem o presente tais como a alta densidade demográfica e a falta de recursos naturais, como água e petróleo, que comprometem a qualidade de vida das pessoas. 
Ao mesmo tempo apresenta uma alternativa que é a substituição do petróleo pela soja, pela água, através de carros com tecnologia inteligente a tal ponto de eles próprios, hoje grandes vilões de emissão de gás carbônico nas grandes cidades, futuramente se tornarem despoluidores do ar. Chama também à participação de todos, desde a mais tenra idade, rumo a um futuro sustentável. Já que segundo o anúncio, a Fiat está fazendo a sua parte, mas apenas ela é insuficiente para construir um futuro melhor, sendo preciso a adesão de todos. Ao comprar um carro da marca Fiat, o consumidor pode se pensar como um cidadão, pois o anúncio aponta para "uma empresa que é socialmente responsável".

O olhar para as principais preocupações socioambientais do presente passa por cima do excesso de veículos nas grandes metrópoles brasileiras e dos problemas que acarreta. $\mathrm{O}$ anúncio tem sete páginas (frente e verso). Na primeira página aparece um menino, Victor, de 7 anos, com as mãos atrás da cabeça e logo acima escrito em letra de forma: "O futuro". Na segunda página, aparece o João, de 13 anos, com a mão sobre o queixo e ao seu lado um texto que diz "no futuro vai ter muito mais gente. Vai faltar água. Vai faltar petróleo. O petróleo vai ser substituído pela soja. Os carros serão máquinas que pensam por si". Na terceira página, uma criança, Gabriela, de 8 anos, com o texto: "um carro que não poluísse a cidade: ao contrário, despoluísse. Esse é o carro que eu desejaria muito para o futuro". Na quarta página aparece Helena, de 4 anos, e logo acima dela um texto escrito: "no futuro muito robô. Muito carro no ar. Coloca carro nele, aperta um botãozinho e sai voando só, com água, limpinho". Na quinta página aparece Giovanne, de 11 anos, com o queixo na mão, e ao lado escrito: “Uma pessoa sozinha não muda o mundo, mas se cada um se mobilizasse um pouquinho dava para melhorar muita coisa, senão, eu tô ferrado. Não só eu: meus filhos, meus netos, meus sobrinhos". Na sexta página, aparece Enzo, um bebê de 7 meses, de bruços, olhando para frente. E na página ao lado, para concretizar os sonhos apresentados por essas crianças, um texto que ocupa uma página inteira, informando:

A Fiat chega aos 30 anos como a montadora líder do mercado no país. Mas a ideia não é comemorar essa data, falando do passado. A Fiat quer falar do futuro. E a primeira coisa que ela fez foi ouvir as pessoas, gente de todas as idades que estão envolvidas de alguma forma com o que fazemos: automóveis. E descobrimos que elas querem ainda mais. A Fiat tem fabricado carros cada vez mais econômicos e que poluem cada vez menos. Mas isso ainda é pouco. Ela recicla anualmente $92 \%$ dos resíduos produzidos na fabricação dos seus veículos. Mas dá para fazer mais. A Fiat sabe como ninguém qual a importância tem os automóveis na vida do Brasil e dos brasileiros. Como objetos de desejo, como meio de transporte indispensável num país do tamanho do nosso. E, também, como veículos de uma empresa que é socialmente responsável. Esse é o futuro, um futuro que nós já começamos. E queremos convidar você para fazer esse caminho com a gente. Não apenas como alguém apaixonado pelos nossos veículos, pelo design, pela tecnologia e pela velocidade. Mas também como cidadão. Por isso mesmo, na nossa companha, participam até pessoas que têm apenas alguns meses de idade. Elas também vão influenciar os nossos produtos e o nosso futuro nos próximos 30 anos. 
Abaixo e em negrito:

"Fiat, 30 anos. Convidando você a pensar no futuro" (REVISTA VEJA, 22/3/2006).

\section{Considerações Finais}

Este artigo buscou refletir sobre as transformações do discurso publicitário e suas relações com o contexto sociocultural. Apontou-se para a importância que as subjetividades adquiriram nas sociedades de comunicação e consumo. Uma das formas mais contundentes pelas quais esse fenômeno se expressa é através da ênfase na vida e, portanto, no homem, presentes nos anúncios publicitários que se apoiam na sustentabilidade e na responsabilidade social. Estas são palavras de ordem que correspondem à colonização de novas áreas pelo capitalismo.

Uma das questões levantadas é que se há uma mudança nos valores expressos nos anúncios publicitários, então, de que forma esses anúncios representam o consumo, já que a responsabilidade socioambiental revestida sob o paradigma da sustentabilidade está supostamente ligada a um tipo de consumo que "atende às necessidades do presente sem comprometer a possibilidade de as futuras gerações atenderem às suas próprias necessidades?". Nesse sentido, enfatizou-se a relação entre a preocupação com o homem e sua responsabilização expressa nos anúncios publicitários cujos valores se ancoram no discurso da sustentabilidade.

Falando em termos foucaultianos (FOUCAULT, 1979), a publicidade aparece como um "dispositivo", cujas técnicas, estratégias e mecanismos de forças presentes em seus discursos revelam a lógica de valorização do indivíduo na sua prática responsável. Isso significa que a responsabilidade social passa a ser do indivíduo pensado como consumidor e não da coletividade estruturada por um agir político para um "mundo comum", como diria Arendt (1998). Anúncios publicitários, como os da Fiat e do Banco Real, analisados, condensam a visão dos anunciantes sobre a sustentabilidade: um paradigma que se baseia no neoliberalismo, cujo alicerce é o capitalismo como modo de vida. Neles, a gestão de si aparece por meio de um suposto ativismo social que se daria a partir da adesão do consumidor aos serviços e produtos ofertados pelo anunciante.

Os anunciantes ao mostrarem que "já fizeram a sua parte", seja através do investimento em tecnologia, reflorestamento, ou participação em ações socioambientais, com institutos e organizações não governamentais, deixam implícita a mensagem de que agora é a vez do consumidor, que deve "fazer a sua parte" comprando mercadorias e serviços oriundos de empresas que se preocupam com a sustentabilidade. Como resultado, estaria aí presente um consumo sem conflito moral, apontado por Fontenelle, porque dimensionado pelo discurso da solidariedade social, tecnologia limpa e da gestão responsável, como explícito no anúncio do Banco Real, que faz questão de mencionar que a sustentabilidade é sua "estratégia de negócios". 
Tarcyanie Cajueiro Santos é doutora e pós-doutora em Ciências da Comunicação pela ECA/USP e professora do Mestrado em comunicação e cultura da Universidade de Sorocaba, Uniso.

tarcyanie@terra.com.br

\section{Referências}

ARENDT, Hannah. O que é política? Rio de Janeiro, Bertrand Brasil, 1998.

CARRILHO, K. Sustentabilidade e responsabilidade socioambiental: transformações culturais na mensagem publicitária. (Tese). Curso de Pós-Graduação em Comunicação Social. Universidade Metodista de São Bernardo, 2010.

DOWBOR, L. "O Conhecimento é um fator de produção e qualidade de vida". In: Consumo consciente e comércio justo: conhecimento e cidadania como fatores econômicos. Rio de Janeiro, Senac Nacional, 2010.

EHRENBERG, Alain. $\mathrm{O}$ culto da performance: da aventura empreendedora à depressão nervosa. São Paulo, Ideias e Letras, 2010.

FONTENELLE, Isleide Arruda. O fetiche do eu autônomo: consumo responsável, excesso e redenção como mercadoria. Psicologia \& sociedade, Florianópolis, v. 22, n. 2, 2010.

FOUCAULT, Michel. "Sobre a história da sexualidade". In: Microfísica do poder. Rio de Janeiro, Graal, p. 243-276, 1979.

"Nascimento da biopolítica". In: Resumo dos cursos do Collège de France (1970-1982). Rio de Janeiro, Jorge Zahar, p. 87-97, 1997.

Arqueologia do saber. Rio de Janeiro, Forense Universitária, 2008.

IASBECK, Luiz Carlos Assis; PEREIRA, Fernanda Mendes Santiago. Gestão de comunicação da marca - branding: Uma abordagem semiótica da marca nas organizações. In: ENCONTRO NACIONAL DA COMPÓS, 20. Anais... Porto Alegre, UFRGS, jun.2011.

JAMESON, Frederic. Pós-modernismo: a lógica cultural do capitalismo tardio. São Paulo, Ática, 1996.

KELLNER, Douglas. A cultura da mídia. Bauru, EDUSC, 2001.

LIPOVETSKY, Gilles. A felicidade paradoxal: ensaio sobre a sociedade de hiperconsumo. São Paulo, Companhia das Letras, 2007.

LUCAS, Luciane; HOFF, Tânia Márcia. Sustentabilidade sócio-cultural no discurso publicitário: o corpo em evidência. Comunicação: Veredas. Revista do Programa de Pós-Graduação em Comunicação. São Paulo, Unimar, n. 5, v. 5, 2006.

MUNIZ, Lygia Maria Perini. A publicidade de marcas como instância legitimadora da sociedade de consumo. Tese de doutorado em Comunicação e Semiótica. São Paulo, PEPG em Comunicação e Semiótica, Pontifícia Universidade Católica de São Paulo, 2004.

PELBART, Peter Pál. Vertigem por um fio: política da subjetividade contemporânea. São Paulo, Iluminuras, 2000.

PORTILHO, Fátima. Sustentabilidade ambiental, consumo e cidadania. São Paulo, Cortez, 2005. 
Revista Veja, edições de 01/01/2000, 01/03/2000, 7/9/2005, 12/9/2005, 28/12/2005, 8/2/2006, 22/3/2006.

ROCHA. Maria Eduarda da Mota. A nova retórica do grande capital: a publicidade brasileira entre o neoliberalismo e a democratização. Comunicação Mídia e Consumo, São Paulo, v. 1, n. 2, 2005.

O canto da sereia: notas sobre o discurso neoliberal na publicidade brasileira pós-1990. Rev. bras. Ci. Soc., São Paulo, v. 22, n. 64, jun, 2007.

TAVARES, Fred; IRVING, Marta de Azevedo. Naturesa S/A? - o consumo verde na lógica do Ecopoder. São Carlos, RiMa Ed., 2009.

WALDMAN, Maurício. Natureza e sociedade como espaço de cidadania. In: PINSKY, Jaime.; PINSKY, Carla Bassanezi (orgs.). História da cidadania. São Paulo, Contexto, p.545-561, 2010.

Artigo recebido em março e aprovado em maio de 2013. 